\title{
Guest Editorial - Novel Insights into the Pathology of Stachybotrys chartarum
}

\author{
Iwona Yike • Dorr Dearborn
}

Received: 20 March 2011/Accepted: 28 March 2011/Published online: 20 April 2011

(C) Springer Science+Business Media B.V. 2011

The adverse health effects of indoor mold exposure gained much public attention in recent years. Although many studies support the involvement of fungi in building-related illnesses and emphasize the importance of mold exposure as an emerging public health issue, the role of toxigenic species such as Stachybotrys chartarum (SC) remains highly controversial [1]. Widespread litigation is making it more contentious, and the existing scientific information does not offer sufficient evidence that could lead to a better understanding of the problem and development of comprehensive public health policies. The article by Nagayoshi et al. [2] published in this issue of Mycopathologia describing for the first time the remodeling of pulmonary arteries in mice as a result of inhalation exposure to the spores of $S$. chartarum significantly extends our knowledge of the pathologic effects of this fungus.

The ability to produce potent trichothecene mycotoxins became a source of great concern about $S$. chartarum. Approximately one-third of the isolates from the United States and Europe represent a chemotype that synthesizes macrocyclic trichothecenes [3]. Macrocyclic trichothecenes are not found in SC isolates belonging to the second chemotype which

I. Yike $(\bowtie) \cdot$ D. Dearborn

Department of Environmental Health Sciences, Case

Western Reserve University, School of Medicine,

Location Code 4940, Room WG19, 2109 Adelbert Rd.,

Cleveland, $\mathrm{OH} 44106$, USA

e-mail: ixy@case.edu produces atranones. However, both chemotypes can synthesize much less potent simple trichothecenes.

Molds can affect human health through mycotoxicosis, infection, allergy, and inflammation. The first category is often disputed, especially in the context of residential indoor air exposure [1, 4]. Arguments against the role of $S$. chartarum in building-related diseases are mostly based on the projection that the relatively low concentrations of the SC spores found in most indoor environments are insufficient to cause severe systemic toxicoses. Such opinions do not take into account local toxic effects at the site of deposition of fungal particles where the toxins can reach millimolar concentrations. Reports focusing on mycotoxins tend to present the "toxic black mold," as $S$. chartarum is known to the public, as a species with unique properties compared with other fungi. While its high toxigenic potential clearly sets it apart, the effects of different fungal compounds common to all fungi such as $\beta$-D-glucan, proteins including hemolysin and proteases or various low-molecular-weight metabolites are likely to play a significant role in pathophysiology of this species [5-9]. In recent years, a number of animal studies of pulmonary effects of $S$. chartarum have been published, utilizing different animals/strains, different fungal isolates, and experimental protocols. The common finding was lung injury and inflammation. Some of those effects were paralleled in the experiments conducted with pure trichothecene toxins or atranones but toxin-independent mechanisms were also postulated $[1,10,11]$. It is 
worth noting that SC spores are much larger than those of other molds and contain higher quantities of fungal molecules compared to the smaller spores of other species [3, 12]. Proteolytic activity of the spores of the non-toxic isolate of $S$. chartarum was shown to be nearly 300 times higher than that of Paecilomyces variotti and more than 150 times higher than in the spores of Penicillium verrucosum [12].

Characterization of allergic responses to $S$. chartarum is of great importance because very low concentrations of antigens present in the environment can elicit strong responses. A number of proteins from $S$. chartarum that are antigenic in humans have been identified, but the association between human disease and the presence of $\operatorname{IgE}$ and $\operatorname{IgG}$ antibodies to this fungus in individuals exposed in mold-contaminated buildings remains unclear [1, 13]. Several animal studies using fungal extracts led to the conclusion that the mold has the capacity to induce allergic responses in mice $[1,14]$. However, in contrast to the extract studies, anti-SC antibodies were not detectable in sera from mice exposed repeatedly to the intact spores [1].

Pulmonary arterial hypertension is a rare disease with a broad etiology ranging from genetic abnormality to forms associated with connective tissue diseases and COPD $[15,16]$. Inflammation appears to be a common feature of PAH [17]. Vascular pathology resulting from exposure to $S$. chartarum was reported in 2008 by Ochiai et al. [18]. The development of pulmonary arterial hypertension was evidenced by the thickening of the arterial walls and right ventricular hypertrophy. This initial finding and the current report coming from the same group [2] support the view that fungi, similarly to some viruses and protozoa, can affect vascular remodeling leading to the development of PAH [19-21]. The results of the new investigation include immunohistochemical demonstration of smooth muscle cell proliferation and hypertrophy in pulmonary arteries of mice treated with $S$. chartarum. Those changes were correlated with increased levels of $\mathrm{TH} 2$ cytokines in the BAL fluid. Pulmonary arterial remodeling was reversible upon cessation of exposure to fungal spores. In addition, observed changes were attenuated by ROCK inhibitor linking them to the activation of RhoA/Rho-kinase pathway, a key system in pulmonary hypertension [22]. Although airway remodeling has not been observed, the significance of these findings for asthma may be considered in light of the postulates that asthma and $\mathrm{PAH}$ share important pathological features [23].

While the work of Nagayoshi et al. [2] presents new pathological aspects of $S$. chartarum, it also raises questions regarding mechanisms that may be involved and calls attention to some of the inherent difficulties concerning the design and interpretation of animal studies of mold exposure. The analysis of the host response at the molecular level clearly demonstrates the link of pulmonary arterial remodeling to TH2 response and activation of RhoA/ROCK pathway, but the fungal components responsible for those effects remain unknown. The effects observed in this study may not be specific to $S$. chartarum unless they can be linked to trichothecenes and/or other metabolites and proteins from this fungus. Since PAH can arise simply from chronic hypoxia [15], in this case it may be secondary to the resulting inflammation and airway obstruction. Strong TH2 response and severe pulmonary arterial remodeling were seen in experiments employing a soluble antigen from Aspergillus fumigatus [24]. Regrettably, Nagayoshi et al. [2] have not searched for the presence of anti-fungal antibodies. Further studies should lead to a more thorough assessment of allergenic capacity of $S$. chartarum in this murine model. In addition, the fact that the spores have been collected from PDA cultures raises the issue of relevance of this investigation to human indoor exposure. It has been shown that the protease and hemolysin content of the spores of $S$. chartarum collected from PDA is higher than in the spores obtained from dry wall cultures [11] and such spores may express antigens not encountered in indoor environment. The authors state that the fungal isolate used in these experiments is capable of synthesizing trichothecenes [2], but it is not clear whether those were of the macrocyclic or the simple type. More detailed characterization of trichothecene toxicity of the spores should also help in better understanding of the precise mechanisms involved in S. chartaruminduced pulmonary arterial remodeling.

\section{References}

1. Pestka JJ, Yike I, Dearborn DG, Ward MD, Harkema JR. Stachybotrys chartarum, trichothecene mycotoxins, and damp building-related illness: new insights into a public health enigma. Toxicol Sci. 2008;104(1):4-26. 
2. Nagayoshi M, Tada Y, West J, Ochiai E, Watanabe A, Toyotome T, Tanabe N, Takiguchi Y,Shigeta A, Yasuda T, Shibuya K, Kamei K, Tatsumi K. Inhalation of Stachybotrys chartarum evokes pulmonary arterial remodeling in mice, attenuated by Rho-Kinase Inhibitor. Mycopathologia. 2011. doi:10.1007/s11046-011-9400-3.

3. Andersen B, Nielsen KF, Jarvis BB. Characterization of Stachybotrys from water-damaged buildings based on morphology, growth, and metabolite production. Mycologia. 2002;94(3):392-403.

4. Chapman JA, Terr AI, Jacobs RL, Charlesworth EN, Bardana EJ Jr. Toxic mold: phantom risk vs science. Ann Allergy Asthma Immunol. 2003;91(3):222-32.

5. Rand TG, Sun M, Gilyan A, Downey J, Miller JD. Dectin1 and inflammation-associated gene transcription and expression in mouse lungs by a toxic $(1,3)$-beta-D: glucan. Arch Toxicol. 2010;84(3):205-20.

6. Vesper SJ, Magnuson ML, Dearborn DG, Yike I, Haugland RA. Initial characterization of the hemolysin stachylysin from Stachybotrys chartarum. Infect Immun. 2001;69(2): 912-6.

7. Yike I, Rand T, Dearborn DG. The role of fungal proteinases in pathophysiology of Stachybotrys chartarum. Mycopathologia. 2007;164(4):171-81.

8. Miller JD, Sun M, Gilyan A, Roy J, Rand TG. Inflammation-associated gene transcription and expression in mouse lungs induced by low molecular weight compounds from fungi from the built environment. Chem Biol Interact. 2010;183(1):113-24.

9. Miller JD, Rand TG, Jarvis BB. Stachybotrys chartarum: cause of human disease or media darling? Med Mycol. 2003;41(4):271-91.

10. Leino M, Mäkelä M, Reijula K, Haahtela T, MussaloRauhamaa H, Tuomi T, Hintikka EL, Alenius H. Intranasal exposure to a damp building mould, Stachybotrys chartarum, induces lung inflammation in mice by satratoxinindependent mechanisms. Clin Exp Allergy. 2003;33(11): 1603-10.

11. Yike I, Dearborn DG. Pulmonary effects of Stachybotrys chartarum in animal studies. Adv Appl Microbiol. 2004;55:241-73.

12. Yike I, Walenga R, Dearborn D. Comparison of the acute effects of S. chartarum and other indoor molds on the lungs of infant rats. In: Johanning E, editor. Fungi, bacteria, mycotoxins and human health. Albany, NY: Fungal Research Group Foundation, Inc.; 2005. p. 170-7.

13. Shi C, Smith ML, Miller JD. Characterization of human antigenic proteins SchS21 and SchS34 from Stachybotrys chartarum. Int Arch Allergy Immunol. 2010;155(1):74-85.

14. Chung YJ, Copeland LB, Doerfler DL, Ward MD. The relative allergenicity of Stachybotrys chartarum compared to house dust mite extracts in a mouse model. Inhal Toxicol. 2010;22(6):460-8.

15. Zakynthinos E, Daniil Z, Papanikolaou J, Makris D. Pulmonary hypertension in COPD: pathophysiology and therapeutic targets. Curr Drug Targets. 2011;12(4):501-13.

16. Essop MR. Contemporary insights into the pathogenesis, diagnosis and therapy of pulmonary arterial hypertension. Cardiovasc J Afr. 2010;21(6):334-7.

17. Dorfmúller P, Perros $\mathrm{P}$, Balabanian K, Humbert $\mathrm{M}$. Inflammation in pulmonary arterial hypertension. Eur Respir J. 2003;22(2):358-63.

18. Ochiai E, Kamei K, Watanabe A, Nagayoshi M, Tada Y, Nagaoka T, Sato K, Sato A, Shibuya K. Inhalation of Stachybotrys chartarum causes pulmonary arterial hypertension in mice. Int J Exp Pathol. 2008;89(3):201-8.

19. Swain SD, Han S, Harmsen A, Shampeny K, Harmsen AG. Pulmonary hypertension can be a sequela of prior Pneumocystis pneumonia. Am J Pathol. 2007;171(3):790-9.

20. Degano B, Sitbon O, Simonneau G. Pulmonary arterial hypertension and HIV infection. Semin Respir Crit Care Med. 2009;30(4):440-7.

21. Souza R, Fernandes CJ, Jardim CV. Other causes of PAH (schistosomiasis, porto-pulmonary hypertension and hemolysis-associated pulmonary hypertension). Semin Respir Crit Care Med. 2009;30(4):448-57.

22. Connolly MJ, Aaronson PI. Key role of the RhoA/Rho kinase system in pulmonary hypertension. Pulm Pharmacol Ther. 2011;24(1):1-14.

23. Said SI, Hamidi SA, Gonzalez Bosc L. Asthma and pulmonary arterial hypertension: do they share a key mechanism of pathogenesis? Eur Respir J. 2010;35(4):730-4.

24. Daley E, Emson C, Guignabert C, de Waal Malefyt R, Louten J, Kurup VP, Hogaboam C, Taraseviciene-Stewart L, Voelkel NF, Rabinovitch M, Grunig E, Grunig G. Pulmonary arterial remodeling induced by a Th2 immune response. J Exp Med. 2008;205(2):361-72. 